\title{
FAILED SPINAL ANESTHESIA; THE INCIDENCE IN A POSTGRADUATE TEACHING HOSPITAL saeeda20022000@yahoo.com
}

1. MBBS, MCPS, FCPS (Anesthesia). Consultant Anesthetist

742-D Faisal Town, Lahore

2. MBBS, MCPS

$\left(2^{\text {nd }}\right.$ year resident at the time of study) 2-WCR Block X New Satellite Town, Sargodha

3. MBBS, $2^{\text {nd }}$ year resident at the time of study

House No. 7, Street No.2, Calcutta House, Katchery Road, Sargodha. 4. MBBS,

$2^{\text {nd }}$ year resident at the time of study, Faiz Memorial Hospital Chowk, Satellite Town Sargodha

Correspondence Address: Dr. Mobeen Ikram MBBS, MCPS, FCPS (Anesthesia).

Consultant Anesthetist

742-D Faisal Town, Lahore

saeeda20022000@yahoo.com

Article received on:

11/01/2016

Accepted for publication:

25/10/2016

Received after proof reading:

00/00/2016

\section{INTRODUCTION}

Spinal anesthesia is a common anesthetic technique for infraumbilical surgical patients. It is now routinely practiced in obstetrics surgery. ${ }^{1}$ About 25 years back, general anesthesia was prefferd over spinal anesthesia in many developed countries of the world including UK. The choice of anesthesia for caesarian section depends on the urgency of surgery, indication of surgery as well as patients desire. ${ }^{2}$

Failure to achieve an adequate level of anesthesia is not only distressing for the patient but also for the anesthetist. ${ }^{3}$ In a teaching hospital a large number of doctors are undergoing their postgraduate training and are in different phases of their training. Based on this, it is expected that chances of failed spinal anesthesia will be more as compared to an institution where spinal injection is being given by senior anesthetist themselves. Internationally failure rate of 0.8 to $1 \%$ in elective and 3 to $4.9 \%$ in emergency caeserian sections is accepted in skilled hands. ${ }^{4}$

\section{MATERIAL AND METHODS}

This study was carried out at PAF Hospital Mushaf, Sargodha from 01 january 2015 to 31 May, 2015 after taking permission from hospital ethical committee. Only obstretic patients who reported to operation theatre for lower section caesarian section (LSCS) were enrolled in the study after informed consent. Both elective and emergency LSCS were included and backup for general anesthesia was ensured. The patients included in this study were between the ages of 18- 40 years, height more than 5 feet 3 inches and weight between $45-75 \mathrm{~kg}$ and were ASA I and ASA II. Exclusion criteria included patients with history of sepsis, severe valvular heart disease, congestive heart failure, spinal deformity, skin infection at lumber region, patient refusal for spinal anesthesia, those who were on anticoagulation 
and patients with deranged coagulation profile or with low platelet count.

The post graduate trainees who have had completed one year residency training in anesthesia and have performed at least 200 spinal anesthetics were enrolled in the study so that they can work under indirect supervision while performing spinal block and at all times patients were supervised by senior anesthetist to avoid any complication or breach of patient trust. The students were taught to call for help if they fail to locate subarachnoid space in two attempts and then spinal anethesia was to be given by senior anesthetist and was to be labelled as failed to locate spinal space in this study.

On arrival in operation theatre in preholding area, patient documents were checked, investigations reviewed and brief preanesthesia assessment was done to rule out any contraindications to spinal anesthesia. Height and weight of each patient was taken and informed consent was obtained.

In the operating room, intravenous line was secured by passing $18 \mathrm{G} \mathrm{IV}$ cannula. Essential monitors were attached and vital signs were plotted on anesthesia proforma and included pulse oximetry, noninvasive blood pressure monitoring (NIBP) and electrocardiogram (ECG). Each patient was prehydrated with $10 \mathrm{ml} / \mathrm{kg}$ of Ringer solution.

After prehydration, each patient was made to sit on the edge of table with legs hanging down from the other side of the table and resting on the stool. All the sterile precautions were taken and area of lumbosacral spine was draped with pyodine.

$2 \mathrm{ml}$ of lignocaine plain $2 \%$ was given with $5 \mathrm{cc}$ syringe as local anesthesia at either L3-L4 or L4-L5 level. Then $1.5 \mathrm{ml}$ of bupicaine $0.75 \%$ was given in the subarachnoid space at L3-L4 or L4-L5 level with $25 \mathrm{G}$ Quincke spinal needle after withdrawing clear flow of cerebrospinal fluid (CSF) in all four quadrants. Finally antiseptic dressing was done.
The patients were made to lie down supine on the table with slight 5-10 degree head down and with left lateral tilt by placing a wedge under the right buttock. Monitors were reconnected with continuous monitoring of pulse oximetry, NIBP and ECG.

All patients were assessed for effectiveness of spinal anesthesia by pain to pin prick and motor blockage by failure of the patients to raise legs.

All the patients made smooth uneventful recovery and were shifted to post anesthesia care unit (PACU) where they were monitored for another half an hour and supplemental oxygen was given. All the patients were then shifted to gynecology ward after fulfilling the discharge criteria.

\section{RESULTS}

In one case where spinal anesthesia could not be given by the trainee nor by the senior anesthetist, was given general anesthesia as this case was elective LSCS and was labelled as failure to locate spinal space.

In two patients spinal anesthesia was given and initially, surgery proceeded as routine. After delivery of the baby, the patient started of complaining pain in the epigastrium which was managed with injection midazolam $1 \mathrm{mg}$ and injection Nalbuphine 3mg intravenously with $100 \%$ oxygen by face mask. Both of these patients were emergency LSCS.

Four patients complained of pain on incision although they could not lift the legs. These patients were managed with injection ketamine $30 \mathrm{mg}$ with $100 \%$ oxygen. The patients became comfortable after injection ketamine and surgery proceeded smoothly without patient discomfort. Three of these patients were emergency LSCS.

In two patients, there was no effect of spinal anesthesia and repeat spinal anesthesia was given with half the initial dose in elective surgery. It helped in achieving the desired effect of spinal anesthesia. However, the second patient was emergency LSCS, repeat spinal anesthesia was 
not attempted and general anesthesia was given.

One patient complained after surgery that she had been pricked thrice for spinal anesthesia. Although, all patients were briefed about the steps of spinal anesthesia, she was counselled along with her husband that failed spinal can occur even in expert hands and the first prick was of local anesthesia while two attempts were made to locate spinal space. Counselling helped in avoiding litigation.

Thus, in elective cases, 03 cases of failed spinal occurred out of total of 293 cases.

In emergency cases, 06 cases of failed spinal occurred, as labouring patient not cooperated in making proper position for spinal injection and also stress on the postgraduate trainee to be quick in performing lumbar puncture was a contributory factor.

\section{DISCUSSION}

Spinal anesthesia was first introduced in 1898 and became popular for infraumbilical surgery. ${ }^{2}$ But later due to large number of complications associated with it like bradycardia, hypotension, post dural puncture headache, backache, cardiac arrest, transient neurological symptoms, it lost popularity. ${ }^{5}$ It was mainly because of inexperienced anesthetist, less knowledge about spinal anesthesia and failure to timely recognize and treat complications. Furthermore wide bore spinal needles and giving spinal at L1-L2 space and causing injury to spinal cord was also associated with high morbidity associated with spinal anesthesia. ${ }^{6}$

In the present era, spinal anesthesia is favored worldwide for obstetrics anesthesia due to avoidance of risk of failed intubation, aspiration pneumonia and better neonatal profile with anesthesia being achieved in 3-5 minutes. ${ }^{2}$ Added advantages include mother being awake can listen cry of the baby at birth, reduced chances of deep venous thrombosis, early immobilization, low cost of spinal anesthesia and shorter hospital stay. The use of small size spinal needles and better understanding of spinal anesthesia has markedly reduced the morbidity and mortality previously associated with spinal anesthesia. ${ }^{5}$

Although spinal anesthesia has its advantages, failure to achieve adequate level of anesthesia after subarachnoid injection can be very distressing as the patients take it as a complication of spinal anesthesia. ${ }^{7}$ The anesthetist has to weigh whether to counsel the patient and explain that she is aware but will not feel pain, to wait for some time to achieve the effects spinal anesthesia, to sedate the patient, to give ketamine, to repeat spinal or to proceed with general anesthesia. ${ }^{3}$ Furthermore, the advantages of spinal anesthesia are lost in case of failed spinal and warrants extra care especially of airway.

There are several reports of failed spinal in literature ${ }^{8}$ and common causes include improper technique, septation in spinal cord, wrong labelling of drug, needle half inside and half outside the subarachnoid space and into the subdural space, improper positioning after spinal anesthesia, inadequate dose, prolonged surgery, previous spinal surgery ${ }^{3}$ and low bupivaine concentration in cerebrospinal fluid in patients with failed spinal anesthesia even in the absence of technical problems. ${ }^{9}$ Repeat spinal anesthesia may have to be given in patients with kyphoscoliosis due to anatomical reasons preventing the spread of local anesthetic ${ }^{10}$ and in addicts in whom tolerance to the drug may be the possible explanation as some of the narcotics have local anesthetic properties. ${ }^{11}$ It thus forces the anesthetist for alternate interventions like repeat spinal or to proceed with general anesthesia which may be less favorable for the patient.

The chances of failed spinal increases when a trainee is asked to give spinal anesthesia urgently for emergency caesarean section as the traditional belief like delay in the readiness of the patient for surgery due to inadequate block affects during the performance of the block. ${ }^{12}$ Furthermore over persuading a reluctant mother for spinal anesthesia is also a cause of failed spinal as the patient takes feeling of touch and pressure as 
inadequate block and do not cooperate during surgery. ${ }^{12}$

\section{CONCLUSION}

The incidence of failed spinal anesthesia in teaching hospital in Pakistan is $3.07 \%$ which is slightly more than target of $3 \%$ of Royal College of Anesthetists where all spinal anesthesia is administered by senior skilled anesthetists.

\section{Copyright(c) 25 Oct, 2016.}

\section{REFERENCES}

1. Nagata J M. Failure of Spinal Anesthesia with Marcaine (Bupivaine): Recent Cluster of Cases. Can J Hosp Pharm 2009 June; 62(3): 255.

2. Siddiqi R, Jafri S A. Maternal Satisfaction after Spinal Anesthesia for Caesarean Deliveries. JCPSP 2009; 19 (2) : 77-80.

3. Fettes P W D, Janson J R and Wildsmith J A W: Failed spinal anesthesia: mechanisms, management, and prevention. Br J Anesth 2009; 102: 739-48.

4. Kinsella S M. A prospective audit of regional anesthesia failure in 5080 Caesarean sections. Association of Anesthetist of Great Britain and Ireland 2008; 63 (8): 822-832.
5. Sikander R I, Haider S. The Pencilpoint Lumbar Puncture Needles: Are they Worth their Price. Ann. Pak. Inst. Med. Sci. 2009; 5 (4): 216-219.

6. Javed S et al. J. Pharm. Sci. \& Res 2011 ; 3 (10): 15301538.

7. Robert M Raw Dept of Aneas, University of Iowa; Ambulatory surgery. Dec 2010, page 99-102.

8. Harrison DA. Spinal anesthesia for urological surgery. A survey of failure rate, postdural puncture headache and patient satisfaction. Anesthesia 1992; 47 (10) : 902-3.

9. Steiner $L A$ et al. Bupivacaine concentrations in lumbar cerebrospinal fluid in patients with failed spinal anesthesia. Br J Anesth 2009; 102(6):839.

10. Kumar R, Singh k, Prasad G, Patel N. Repeat spinal anesthesia after a failed spinal block in a pregnant patient with kyphoscoliosis for elective caesarean section. J Obstet Anaesth Crit Care 2014; 4: 84-6.

11. Youssef M M I, Abdeilnaim HE. Failed Spinal anesthesia in addicts: Is it an incidence or coincidence? Egyptian Journal of Anaesthesia 2014; 30 (3): 247-253.

12. Ismail S, Shafiq F, Mailk A. Technique of anesthesia for different grades of caesarean section: A cross - sectional study. Journal of Pakistan Medical Association 2012; 62 (4): 363-7.

\section{AUTHORSHIP AND CONTRIBUTION DECLARATION}

\begin{tabular}{|c|l|l|}
\hline Sr. \# & \multicolumn{1}{|c|}{ Author-s Full Name } & \multicolumn{1}{|c|}{ Contribution to the paper } \\
\hline 1 & Dr. Mobeen Ikram & Original manuscript writing \\
2 & Dr. Abdul Samee & $\begin{array}{l}\text { Active participant, Adminstered } \\
\text { spinal anesthesia, Assistance } \\
\text { in typing } \\
\text { Active participant, Adminstered } \\
\text { spinal anesthesia,Assistance in } \\
\text { Graphes and tables } \\
\text { Assistance in printing and } \\
\text { references }\end{array}$ \\
\hline 4 & Dr. Muhammad Amir & Dr. Muhammad Imdad
\end{tabular}

